\title{
Temas de reflexión en la intervención social ${ }^{1}$
}

\author{
José Darío Sáenz
}

\begin{abstract}
Nowadays, social intervention faces certain contradictions which come from the wide diversity of objectives, actors, principles and practical elements that are necessary for its implementation. The author examines here some of these tensions from the perspective of the historical formation of social intervention, and the changes that its actors and concepts have undergone. The article also presents some of the more formal models in the intervention process and reflections on these from renowned authors on the subject.
\end{abstract}

\section{Dinámica histórica}

La intervención social se suele entender como una acción organizada de un conjunto de individuos frente a problemáticas sociales no resueltas, en donde participan por lo menos tres actores claves de intervención: el Estado definiendo políticas sociales, algunas formas organizadas de la sociedad civil - como las ONG - a través de acciones públicas sociopolíticas, y el mundo académico con la construcción de discursos y teorías que de alguna manera orientan las prácticas de intervención social. La intervención social constituye ante todo un proceso de orden racional, pues se funda en una intención manifiesta de modificar o transformar una situación que se considera indeseable e injusta socialmente, ante todo para el grupo que la padece. La intervención, como se suele presentar, no requiere que el grupo o la totalidad del grupo intervenido identifiquen la situación indeseable, ni hace indispensable su participación para la solución de la misma. La intervención se basa en una determinada consideración prescriptiva, en una valoración de los actores intervinientes y a su vez, en una categorización de los intervenidos, bien sea como vagabundos, miserables, pobres, minusválidos sociales, desplazados o, jóvenes

\footnotetext{
${ }^{1}$ Este artículo es producto de un trabajo de investigación, adelantado por el grupo de investigación sobre "Intervención Social” que pertenece al Centro de Investigaciones en Estudios Sociales y Jurídicos, CIES, del Departamento de Humanidades y Ciencias Sociales de la Universidad ICESI. El autor agradece la colaboración de las investigadoras Ana Lucía Paz y Viviam Unás y los aportes del profesor Enrique Rodríguez.
} 
delincuentes, en alto riesgo, etc. Así, hay una suerte de construcción previa del “intervenido”, que pasa por formas de representación social y jurídica que la oficializa como realidad social, y que a su vez define los medios y la situación del proceso de intervención específicos.

Es preciso señalar que la noción “intervención social” es un término en disputa como forma de clasificación y categorización de las realidades sociales, pues el misterio de nombrar, denominar y designar realidades, se constituye en una forma de imposición simbólica capaz de configurar circunstancias, papel clave del Estado en la sociedad moderna. El acto de nombrar crea e implica relaciones de poder y autoridad.

Las dinámicas de intervención social pueden considerar diferentes tipos y niveles de acción pública, desde la asesoría, investigación, capacitación, gestión, planificación y dinamización comunitaria hasta procesos productivos. A su vez, los ámbitos societales en que se desarrolla se distinguen en términos de sectores, grupos o categorías en las que se puede incidir: la comunidad en general, los jóvenes, la tercera edad, los discapacitados, el grupo familiar, infancia, mujer, minorías étnicas, ambiental, ecológica y ecoturística, desarrollo social, educación, entre otros. Si bien la protección de los individuos y la integración social es una problemática constitutiva de todas las sociedades, los procesos de intervención que tratan de conjurarlos han surgido de condiciones históricas específicas. Como veremos, las formas, los actores, los métodos y contextos varían en el tiempo, así como de una cultura a otra.

La configuración del Estado moderno, el surgimiento de los regímenes democráticos y el desarrollo de la ciudadanía, se constituyen en el marco político de los nuevos procesos de intervención. El desarrollo de las tradiciones generacionales de derechos civiles, políticos, sociales y colectivos; el desarrollo industrial y la vinculación de grandes sectores de población en la producción capitalista, el crecimiento de las ciudades, entre otros, se constituye en el marco contextual de la intervención moderna. Mientras en las sociedades premodernas se establecían formas de protección fundadas en el vínculo cercano, ${ }^{2}$ constituido por las pertenencias familiares, de vecindario o trabajo, por el contrario, durante los procesos de disolución de las sociedades feudales surgen instituciones especiales y especializadas (hospitales, orfelinatos, etc.) que pasan a asistir al desvalido, al individuo

${ }^{2}$ Castel, Robert, Las metamorfosis de la cuestión social: Una crónica del salariado, Paidós, Buenos Aires, 1995. 
fragmentado socialmente. Así, hallamos una dinámica social institucionalizante que busca protegerlos e integrarlos socialmente, frente a las condiciones materiales de precariedad en que viven. Por ejemplo, ante los procesos de desafiliación social, señala R. Castel, que la Iglesia asume una postura ambivalente entre la conmiseración y el desprecio por los pobres, los mendigos y los vagabundos. Sus prácticas oscilaron entre una suerte de “economía de la salvación” (el pobre como medio privilegiado para que el rico pueda ejercer la virtud cristiana de la caridad) de un lado y, una percepción discriminatoria de los pobres (materializada en la clasificación entre "buenos pobres”, como quienes más exhiben el sufrimiento en el cuerpo, lo que genera toda una dramaturgia social del dolor y la miseria, y "malos” pobres, como quienes se rebelan al orden establecido y no aceptan su condición de pobreza).

De otro lado, las autoridades políticas asumen tímidamente el problema creciente de la desafiliación con formas de política social sin Estado, que se concretan en la creación de instituciones hospitalarias y orfelinatos. Estas iniciativas, sin embargo, no lograron detener el incremento de individuos marginados. Hacia el siglo XVI, las crisis de subsistencia, el dilatado subempleo, el aumento de los precios de los alimentos, la recuperación demográfica después de la “peste negra” y el crecimiento de las ciudades, dificultaban las posibilidades de afiliación de muchos sujetos sociales. La Iglesia continuaba asumiendo roles importantes en las prácticas de intervención como caridad hacia los marginados, y las autoridades políticas actuaban con ambivalencia frente a los grandes grupos de población en condiciones de precariedad. Las prácticas de asistencia social se organizaban en dos sentidos: por un lado, acciones preventivas que pretendían adelantar funciones pedagógicas para posibilitar la inclusión social (por ejemplo, en los hospitales se combinaba la oración, el trabajo forzado, la disciplina y la reeducación), y por otra parte, las prácticas represivas legales contra personas reincidentes en la actividad del vagabundeo y la mendicidad.

La pauperización social, el desempleo y la inestabilidad laboral producto de los procesos de industrialización, suscitaron amplios debates y luchas en torno a la necesidad de establecer una política social, ya no sólo como deber moral sino como obligación jurídica. Así, frente al riesgo de fractura social hacia finales del siglo XIX y principios del XX en Francia y el occidente europeo, se posibilitaron diversas formas de protección social (las tecnologías del Seguro, por ejemplo), bajo concepciones modernas de propiedad (social), que configuraron lo que reconocemos hoy como Estado del Bienestar. 


\section{Actores que ejecutan intervención social: Estado y sociedad civil}

Es posible identificar al menos dos grandes actores claves en los procesos de intervención social actuales: el Estado y algunos sectores organizados de la llamada sociedad civil. Estos desarrollan su intervención a través de por lo menos cinco formas clásicas. En primer lugar, las formas de sociabilidad primaria a partir de las relaciones con el vecindario, la familia y la adscripción al mundo del trabajo. En segundo lugar, las prácticas de caridad adelantadas desde la Iglesia para con los marginados. En tercer lugar, las formas de solidaridad más modernas, ejecutadas por las instituciones municipales de beneficencia pública para con los pobres y mendigos. En cuarto lugar, las concepciones y prácticas contemporáneas de filantropía social ejercidas desde sectores dominantes y, en quinto lugar, la asistencia social que, como política pública se adelanta desde el Estado, particularmente del llamado “Estado del Bienestar” que pretende generar seguridad social extendida a todos los ciudadanos en la forma de derechos sociales y públicos.

Desde las formas de intervención ejercidas por el Estado del Bienestar, ${ }^{3}$ se conciben dos tipos de actividades centrales: en primer lugar, la provisión estatal, ya sea a través de la entrega en efectivo o en especie de servicios sociales a individuos o familias en circunstancias de vulnerabilidad, con miras a garantizar seguridad social, sanidad, beneficencia, educación y vivienda. En segundo lugar, la reglamentación estatal de actividades privadas, ejercidas por individuos o corporaciones que directamente alteran las condiciones inmediatas de vida de los individuos y grupos dentro de una población y que, más que "mejorar", afectan la situación en términos cuantitativos y cualitativos. Esta reglamentación se concreta en una serie de normas, leyes y obligatoriedades destinadas a “la utilización del poder estatal para modificar la reproducción de la fuerza de trabajo y para mantener a la población no trabajadora en las sociedades capitalistas”. 4 Así, los medios más importantes de los que dispone el Estado para el trabajo de intervención son: la concesión directa de beneficios y servicios, la utilización paralela del sistema de impuestos y la regulación estatal sobre las actividades privadas de individuos y sociedades.

Desde los sectores no estatales se puede hacer referencia a tres formas institucionalizadas de intervención social: la Iglesia, las organizaciones filantrópicas

\footnotetext{
${ }^{3}$ Cf. Ian Gough, Ian, Economía Política del Estado del bienestar (1979), H. Blum Ediciones. Madrid, 1982.

4 Ibíd., p. 111
} 
organizadas generalmente desde sectores pudientes de la sociedad y las organizaciones no gubernamentales (ONG). Tradicionalmente, las prácticas de intervención emprendidas desde la Iglesia se han reconocido como prácticas de caridad cuyo objetivo central es el alivio del infortunio de quienes se hallan en situación de pobreza o indigencia. Para la práctica filantrópica, el asunto está centrado en la conformación de instituciones que logren prevenir la desdicha de quienes padecen las diferentes formas de precariedad material, no sólo a través del socorro individual, sino también a través de la toma de medidas y acciones más generales y de forma institucionalizada. Históricamente las acciones filantrópicas se han planteado la construcción de condiciones de anticipación a los males causados por la indigencia, por ello la constitución de las Cajas de Ahorros y las Sociedades de Socorro Mutuos fueron claves en la rehabilitación moral de los sectores miserables desde una óptica de la previsión social. Sin embargo, es necesario considerar a la acción filantrópica como un lugar intermedio entre la buena voluntad y fraternidad para con los semejantes y una acción que implica control y orden social. En este último sentido, la acción filantrópica requiere de quienes son objeto de la misma una disposición a aceptar un orden de valores y normatividad establecido. La filantropía en no pocas veces se ha constituido entre otros, en uno de los factores que permiten a las élites de poder apuntalar las formas de dominación social y política a partir de acciones de protección, desarrollo, promoción comunitaria y social en general. Por supuesto no como acción racional y orientada en tal sentido por los sectores dominantes, así como tampoco es recusable el sentido de “amor por el prójimo”.

Otra forma extendida del ejercicio de la intervención social no estatal proviene de las ONG. Éstas surgen entre otras razones, por el paulatino desmantelamiento de las instituciones que administraron la asistencia social durante el denominado Estado del Bienestar. Estos actores sociales se caracterizan porque su acción se desarrolla por fuera de lo político (el Estado), pero adelantan prácticas políticas en tanto acciones que busca incidir en lo público, pero actuando como entes privados. A su vez, disputan ciertos espacios públicos con actores sociales de mayor tradición como los partidos políticos, los grupos de presión, los grupos de interés y con las nuevas formas de acción social adelantadas por los movimientos sociales, fundamentalmente. Con estas formas organizadas de la sociedad civil el Estado trata de mantener la responsabilidad pública desde una gestión privada de los servicios sociales. Así, de cara a la crisis de las instituciones de representación tradicionales (sindicales, partidistas, por ejemplo), las ONG emergen con fuerza en la asunción de responsabilidades y funciones públicas. 


\section{Tensiones de la intervención social}

Como ya señalamos, frente a la crisis del Estado de Bienestar se reconfigura su papel como ejecutor de prácticas de asistencia. Emergen nuevos actores que intervienen lo social, lo que origina la aparición de por lo menos tres tipos de tensiones que atraviesan los procesos de reconocimiento social de las instituciones interventoras $\mathrm{y}$, a su vez, esbozan condiciones contextuales ineludibles para pensar la intervención social hoy. Veamos:

A) Actividad sin ánimo de lucro versus escenario laboral remunerado.

Las importantes sumas de recursos económicos para la ejecución de proyectos sociales convierte el campo de la intervención social en un mercado competido, con importantes fuentes de financiación y flujo continuo de capitales. ${ }^{5}$ Esto contribuye a que tanto instituciones de orden estatal como ONG's se constituyan hoy por hoy en un vigoroso escenario laboral, soportado por instituciones con tradición, estabilidad económica y experiencia en la gestión y ejecución de proyectos sociales. Emerge entonces una compleja situación que cuestiona la labor no lucrativa de la intervención social y que revela dilemas éticos e ideológicos a los que los interventores deben enfrentarse cotidianamente. Por ejemplo, estas instituciones y los actores sociales que las constituyen garantizan su supervivencia económica por la existencia de problemáticas que, al mismo tiempo intentan afectar o transformar. Su acción, al menos idealmente, debería orientarse hacia la construcción de situaciones sociales en las que su trabajo no sea ya necesario ni urgente. Es probable que este dilema no afecte de manera directa las prácticas de intervención, la seriedad de los procesos ejecutados y el compromiso de los sujetos interventores, pero sí opera como determinante en los discursos y compromisos ideológicos que las ONG y las instituciones del Estado producen para justificar su labor y distinguirse de las "industrias de la caridad”.

Por otro lado, la condición de "sin ánimo de lucro" se relaciona directamente con las ONG, pues éstas soportan su compromiso ideológico en objetivos diferentes a los fines económicos. Esta condición, sin embargo se ve amenazada por la lógica de competencia en el mercado de proyectos sociales, pues las entidades contratantes, entre ellas el Estado,

\footnotetext{
5 Por ejemplo en la ciudad de Cali para el 2005 hallamos cifras importantes que provienen de transferencias del Estado Central, de recursos de crédito con la banca internacional (fundamentalmente el B.I.D) y, de los recursos propios.
} 
demandan de las ONG un patrimonio propio que garantice su sostenibilidad. Es decir, exigen que las instituciones ejecutoras de proyectos sociales cuenten con activos, pasivos y capacidad de contratación expedida institucionalmente. Sin embargo, rara vez los marcos de referencia de las convocatorias a proyectos garantizan rubros para el pago de gastos administrativos o para la constitución de formas de capital y patrimonio. Esta situación pone a las ONG en una encrucijada, pues por un lado deben presentarse como sostenibles para competir por la asignación de proyectos pero, al mismo tiempo, estas convocatorias no conciben gastos administrativos que avalen dicha sostenibilidad. Así pues, las estrategias que las ONG ponen en juego para sortear esta situación implican una lógica financiera y de economía de recursos que controvierten su condición de organizaciones sin ánimo de lucro.

B) Intervención social no gubernamental versus crisis del Estado de Bienestar

En las sociedades modernas es sin duda el Estado el ente con mayores recursos, posibilidades de gestión y capacidad organizativa para generar procesos efectivos de intervención social. Las instituciones de asistencia, asociadas al Estado del Bienestar, están claramente normatizadas por una serie de obligaciones relacionadas con el papel del Estado como protector de servicios y generador de orden social. Ante la crisis de este tipo de Estado, eficiente e interventor -al que R. Castel denomina Estado Social- y la emergencia de nuevos actores que intervienen lo social desde el ámbito privado o semipúblico, la noción de “obligación estatal” o “función social” se disuelve. Las ONG no están entonces obligadas a apostar por la provisión de servicios sociales predeterminados, su acción se juega en un espeso, y relativamente autónomo, marco de decisiones y voluntades políticas. El desplazamiento de las intervenciones ejecutadas sobre criterios de clase social a las intervenciones sectoriales, etarias, culturales y educativas, constituye un síntoma del repliegue de la intervención en escenarios concretos, mediados por categorías y principios que superan los determinantes socioeconómicos, que no se rigen ya por la imposición de proveer seguridades sociales básicas. Así pues, la intervención social pasó de ser una práctica inherente a la función del Estado y por lo tanto de cierto modo incuestionable, a un escenario indeterminado en el que instituciones y actores se ven abocados a la búsqueda de un espacio legítimo en el campo de la intervención y en el espacio político, como instituciones que buscan, tal vez, algunas transformaciones sociales o movilizan los intereses de grupos concretos. Sin funciones sociales preestablecidas de forma institucionalizada o reglamentada, las ONG y la intervención social que ejecutan se 
enfrentan a un ejercicio de redefinición constante de objetivos, escenarios y principios que regulen sus acciones y su relación con el Estado y la población beneficiaria.

El carácter no gubernamental de las ONG puede interpretarse en dos sentidos; por un lado, éstas son instituciones sin vínculos estatales y por otro, difieren de las lógicas de acción gubernamental y estatal en tanto redefinen lo público como un espacio más amplio que lo circunscrito al accionar del Estado. Así pues, conciben la participación en la ciudad y la ciudadanía en la producción de lo público, lo que las convierte en importantes terrenos de participación y profundización democrática. Su carácter no gubernamental, además, contribuye a su legitimidad y reconocimiento como instituciones eficaces y eficientes en los procesos de cambio y transformación social, al menos como percepción frente a la crisis de lo político estatal y en contraposición a los desacreditados gobiernos y partidos políticos.

Su condición no gubernamental es cuestionada sin embargo, por un hecho concreto: la mayor parte de los proyectos que desarrollan las ONG son contratados con el Estado, lo que indica que ellas se constituyen en ejecutoras de las políticas estatales, de las políticas públicas definidas y determinadas desde las instancias de decisión política estatal. En este sentido, el papel que las ONG cumplen como agentes alternativos de cambio y transformación se ve matizado por la adaptación a las condiciones y problemáticas previamente determinadas por el Estado, su financiador. Por lo tanto, esta situación demanda de las ONG la puesta en juego de una serie de estrategias orientadas a mantener el equilibrio entre la dependencia estatal y los objetivos societarios de la organización, entre el compromiso contractual de la ejecución de políticas del Estado y la correspondencia con los intereses de las poblaciones beneficiarias de la gestión y ejecución de programas y proyectos sociales. De la salida que den las instituciones a la señalada tensión se define de alguna manera el carácter político de la misma.

C) Política compensatoria versus vehículo de transformación y cambio

En general las prácticas de intervención social ejecutadas desde el Estado o desde otras instituciones no gubernamentales han sido fuertemente cuestionadas como reales agentes de cambio social. Por ejemplo, se afirma que el Estado de Bienestar (modelo en sociedades capitalistas) asume el papel de asistencia y apoyo a los sujetos víctimas de la actividad mercantil que el mismo Estado agencia. Por otro lado, se sostiene que el trabajo de asistencia estatal intenta atenuar el conflicto de clases, manteniendo un falso equilibrio que 
contiene, sin hacerlas visibles, las contradicciones sociales y por lo tanto restringe las posibilidades de cambio. ${ }^{6}$

Con respecto a las ONG, su papel como gestoras de cambio social y representantes de la sociedad civil, es puesto en discusión también por su condición de ejecutoras de políticas públicas o planes que provienen de organismos de financiación internacional. Así, los proyectos que desarrollan no necesariamente coinciden con sus intereses y concepciones políticas y sociales. El carácter asistencialista de los proyectos que ejecutan, diseñados para atender los efectos devastadores de las lógicas de ajuste y mundialización capitalista, amenazan las pretensiones de un positivo desarrollo social que pueden movilizar las ONG, en tanto contribuyen a mitigar las condiciones de vulnerabilidad pero no las resuelven y en algunos casos tienden a perpetuarlas. A esto se suma el hecho de que la eficacia de la gestión de las ONG se evalúa a través del uso de indicadores de resultados que, además de limitar la posibilidad de generar procesos sostenibles a largo plazo, convierten los planes de intervención en respuestas coyunturales a urgencias sociales, evidenciadas por mediciones estadísticas de cobertura ampliada.

De otro lado, el trabajo de asistencia que efectúan algunas ONG favorece la dinámica de liberación del Estado de sus responsabilidades en lo que compete a la protección social. La incorporación de las ONG a la prestación de servicios sociales, suele acompañarse de la desarticulación del servicio y de las instituciones que lo regulaban. Esto, por supuesto secunda la desprotección de los beneficiarios. Es claro que las ONG tienen grandes limitaciones para influir y ejecutar políticas públicas, pues dependen de la financiación estatal, lo que las hace frágiles en los procesos de negociación con el Estado o con los organismos económicos internacionales. ${ }^{7}$

Por último, su dependencia de la financiación pública y su subordinación al modelo dominante, de alguna manera las distancia de las organizaciones populares, tiende a burocratizarlas y les puede reducir la posibilidad de intervención transformadora en los problemas reales. A su vez, pueden ser utilizadas para legitimar las políticas de las instituciones públicas, como supuestos interlocutores válidos de la sociedad civil, con lo que contribuyen a la desestructuración social y al “déficit” democrático, pues su poder y

\footnotetext{
${ }^{6}$ Cf. Offe, Claus. Contradicciones en el Estado del Bienestar (1988). Alianza Editorial S.A., Madrid, 1990.

${ }^{7}$ Cf. Serrano O., Maite, "Las ONG en la encrucijada: Del Estado del Bienestar a la Franquicia del Estado", en: Revilla B., Marisa (ed), Las ONG y la política, Ediciones Istmo, Madrid, 2002.
} 
presencia tiende a desmovilizar, suplantar y deslegitimar a las organizaciones populares y de base. ${ }^{8}$

El modo como las ONG resuelven la contradicción entre su papel como agentes de cambio y su participación en procesos que reproducen "un estado de cosas establecido" depende en buena medida de las relaciones que instauran con la comunidad beneficiaria y las estrategias que ponen en juego para, aún considerando el carácter de corto plazo de los proyectos de intervención, liderar y garantizar procesos sostenibles de cambio social.

\section{Principios, métodos y modelos evaluativos}

Frente a las tensiones y condiciones contextuales descritas, en el desarrollo de los procesos de intervención social se han configurado una serie principios, elementos metodológicos y técnicos, así como modelos de evaluación que insinúan o configuran modelos de intervención social.

Algunos de los principios que orientan los procesos de intervención actuales se pueden agrupar en tres discursos, veamos:

\section{A) El sujeto intervenido como actor social}

Las condiciones relacionales de desigualdad en las que se desarrolla la asistencia social (que implican el encuentro entre dos grupos sociales desiguales, donde uno es beneficiario de servicios y por lo tanto considerado vulnerable, y el otro interventor y en apariencia no vulnerable), hace más compleja una interacción sobre la base de respeto y autonomía desde el sujeto intervenido. Este último se encuentra de hecho en una situación de desigualdad con respecto a los agentes interventores lo que favorece la producción de relaciones de dependencia y limita la autonomía de los sujetos. Es necesario considerar que la autonomía ${ }^{9}$ no es simplemente una acción, es una relación en la que debe aceptarse que el otro no es del todo comprensible, es decir que hay aspectos del “otro" no aprehensibles y que son estos aspectos los que precisamente propician permanencia e igualdad en la relación. Así, la

\footnotetext{
${ }^{8}$ Ibíd.

9 Cf. Sennett, Richard, El respeto. Sobre la dignidad del hombre en un mundo de desigualdad, Anagrama, Barcelona, 2003. (p. 183).
} 
autonomía supone conexión y a la vez alteridad, intimidad y anonimato. En las prácticas de intervención sin embargo, la atención por la autonomía constituye un complejo conjunto de retos y definición de límites que garanticen la producción de relaciones de respeto con los sujetos intervenidos. Por ejemplo, el Estado del Bienestar tuvo dificultades para intervenir y al mismo tiempo, tratar con respeto a los beneficiarios de su intervención, pues el principio de la relación involucra una lógica de desigualdad jerárquica entre los actores estatales y comunitarios. Por su parte, la intervención que efectúan las ONG, considerando la ausencia de deberes que predeterminen institucionalizadamente su función, suele preguntarse con insistencia por la búsqueda de estrategias y modelos que se opongan a cierto asistencialismo de las prácticas estatales y posibiliten la participación de los beneficiarios en la búsqueda colectiva de soluciones a sus problemáticas, a la satisfacción de sus necesidades, en un plano de mayor equidad en las interacciones que implica la intervención. Así, frente al problema del respeto y la autonomía, el discurso sobre la participación emerge como una estrategia pedagógica y práctica que pretende construir relaciones más igualitarias entre interventores e intervenidos en los procesos de intervención.

B) Configuración de condiciones más igualitarias en la relación

La relación desigual entre interventores e intervenidos, y la necesidad de construir un trato respetuoso entre unos y otros, entrañan tanto aspectos estructurales como aquellos que atañen a la personalidad. En relación con los aspectos que competen al sujeto, la producción de respeto exige la presencia de algunos procesos simultáneos: prácticas en las que los sujetos hacen algo por sí mismos y prácticas en las que los sujetos hacen algo por los demás. Garantizar el desarrollo pleno de estos procesos pasa por honrar las diferencias y talentos en los logros prácticos, admitir las justas reivindicaciones de la dependencia adulta y permitir a la gente participar más de su propio cuidado. ${ }^{10}$

Sennett profundiza en este aspecto, considerando el papel que la compasión juega en el ejercicio de ayudar a otros a superar sus necesidades. Actuar compasivamente podría ser el resultado de una forma sentimental, movida por la búsqueda de bienestar y en algunos casos de salvación; el trabajo de asistencia social, en cambio, supone que la compasión está inspirada por el deseo de hacer el bien. En ambos casos, sin embargo, la compasión

\footnotetext{
${ }^{10}$ Ibíd., p. 263.
} 
contribuye a afirmar la desigualdad y destruye la idea de solidaridad entre iguales. Dar a los otros puede constituir una forma de manipularlos o también puede ser el mecanismo para afirmar algo en nosotros mismos. De esta manera se establece una conexión entre prodigalidad y servilismo. Por ejemplo, cuando se dona, se considera al otro como carente y desigual y, al mismo tiempo, se construye un medio para ejercer poder sobre los demás. El que dona ejercería entonces un dominio sobre el beneficiario y a su vez obtendría una reafirmación de su propio potencial. La donación se puede convertir en un peligroso vehículo que reproduzca el servilismo y fortalezca el poder de los donantes, independientemente de las razones que inspiren sus iniciativas.

La opción más usual para combatir esta situación, implementada por algunos países desarrollados en sus prácticas de asistencia social, consiste en evitar la asistencia emocional, minimizar los aspectos subjetivos de la dependencia. La asistencia emerge entonces como una obligación unificada. Sin embargo, lo cierto es que la prestación impersonal de servicios constituye una visión empobrecida del trabajo de intervención pues impide el contacto humano que se requiere para una adecuada y respetuosa asistencia del otro. $^{11}$

Algunos discursos de la intervención pretenden lidiar con las consecuencias de la compasión, sin afectar las ventajas de la vinculación emocional entre interventores e intervenidos. En este sentido determinados modelos de intervención proponen un trabajo continuo de reconocimiento de los saberes de la comunidad beneficiaria. Esto implica a su vez un ejercicio de reflexión y cuestionamiento sobre la idea tradicional de conocimiento, ciencia y práctica. Con respecto a la ciencia, la "Investigación Acción Participativa” (IAP), ${ }^{12}$ por ejemplo, la percibe como un producto cultural humano y por lo tanto cargada de prejuicios, valores e ideologías. Así pues cuestiona sus pretensiones de neutralidad y favorece la construcción de un conocimiento científico teleológico, es decir, con fines determinados por la voluntad humana de revelar y transformar el orden social imperante. De la misma manera la IAP, soportada por algunas ideas de A. Gramsci sobre la cultura popular, no concibe las diferencias clásicas entre el trabajo intelectual y el trabajo manual. Todo trabajo manual exige una puesta en juego de trabajo intelectual y todo trabajo

\footnotetext{
${ }^{11}$ Ibíd., p. 148.

${ }^{12}$ A Orlando Fals Borda es a quien se le adjudica la paternidad de la I.A.P. En sus desarrollos participan: Gustavo de Roux, María Cristina Salazar, Heinz Moser, John Jairo Cárdenas. Surge en la década de los 70 como una forma alternativa de asumir la Intervención Social comprometida políticamente con los sectores campesinos y populares.
} 
intelectual demanda para ser legitimado, de un ejercicio manual que lo objetive. Emerge entonces la noción de intelectual orgánico, es decir, un académico que además de dirigir su saber científico hacia compromisos políticos, es un ejecutor y productor de acciones concretas. En este mismo sentido, si el trabajo intelectual no es sólo propiedad de los “intelectuales”, el saber de las comunidades debe ser reivindicado a través de lo que A. Gramsci denomina una “filosofía espontánea” -contenida en el lenguaje, en el sentido común y en el sistema de creencias y folclor- que, aunque incoherente y dispersa, tiene valor para articular la práctica al ámbito de lo popular. Es una práctica que intenta romper con la división social del trabajo académico entre quien desarrolla el trabajo intelectual y el práctico, pues tiende a ponerlos en igualdad de condiciones y a validar los conocimientos populares y científicos.

De otro lado, las condiciones estructuradas de desigualdad en las que se funda la intervención estatal dificultan la “distribución” equitativa del respeto como base de las relaciones entre sujetos sociales. Por ejemplo, las lógicas de relación en que se estructura el Estado contemporáneo posterior al Estado de Bienestar, así como las relaciones económicas que propugna el neoliberalismo, no dejan espacios para unas relaciones más igualitarias y de respeto en los procesos de intervención social. Actualmente la configuración del Estado Social de Derecho intenta llevar al plano constitucional la responsabilidad social y económica del Estado, fundamentalmente para con los sectores más desprotegidos y vulnerables de la sociedad. Se supone que esta nueva versión de Estado Social debe romper con el tipo de relaciones de dependencia y desigualdad que estructuraba en sus prácticas asistencialistas el Estado de Bienestar.

\section{C) Concepción política de la intervención social}

La concepción de praxis social recogida en el modelo de IAP ha sido entendida como relación dialéctica entre práctica y teoría, orientada al cambio y transformación social desde lo popular. En este orden de ideas, Carballeda, ${ }^{13}$ por ejemplo, respalda la idea de una práctica transformadora que permita imprimir nuevos sentidos en la vida cotidiana del otro a intervenir. Desde esta perspectiva, se adelantan fuertes críticas a la intervención y a su real eficacia como vehículo de cambio y emancipación comunitaria. Esta crítica se fundamenta en la relación, en apariencia inevitable, entre asistencia social y capitalismo,

\footnotetext{
${ }^{13}$ Cf. Carballeda, Alfredo. La intervención en lo social. Exclusión e integración en los nuevos escenarios sociales. Editorial Paidós SAICF, Barcelona, 2002.
} 
pues, si la intervención social depende de las instituciones que establecen las coordenadas básicas de lo establecido y de las consecuencias nefastas del mismo, entonces habría que preguntarse si efectivamente buscan cambios que atenten contra la estabilidad de las estructuras dominantes. Si bien este cuestionamiento no niega los alcances de los procesos de intervención social, sí brinda otras perspectivas a sus efectos, pues no todos los procesos de intervención dependen exclusivamente de las instituciones estatales ni tampoco todas las intervenciones estatales se ejercen de manera monolítica para ajustar un orden social desigual. En ese sentido, podría afirmarse que más que cambios sociales, la intervención permite movilizar resistencias y nuevas posibilidades, así como hacer visibles problemas sociales; puede constituirse en un vehículo de luchas que propendan por la integración y reconstrucción de lazos sociales debilitados y, desde estas posibilidades, emerger como un intersticio de libertad desde el que es posible modificar situaciones societales. Esta posibilidad de impactar espacios sociales se juega en medio de la crisis de la modernidad y la emergencia de un futuro incierto, generado, entre otras razones, por la crisis del Estado de Bienestar y el deterioro del mundo del trabajo como escenario para el despliegue de identidades y proyectos vitales, con lo que se han expandido los espacios y formas de exclusión social. En este sentido, la concepción política de la intervención social debe orientarse en dos vías: por un lado, hacia una preocupación por la fragmentación de la sociedad y la vulnerabilidad de los sujetos no integrados y, por otro, hacia las consecuencias de la globalización en la vida cotidiana (en particular hacia los nuevos modos de disciplinamiento y control social ligados al consumo como escenario privilegiado para la construcción de la identidad, entre otros).

¿Cómo se puede desde el mundo académico poner en discusión y problematizar las concepciones, los discursos, los códigos, las formas de clasificación y ordenación de las subjetividades que establecen ciertas instituciones de la realidad social desde la intervención? La academia puede jugar un papel definitivo en la modificación de los imaginarios que alimentan dicha realidad social. Ello requiere, en primer lugar, de una renuncia a la reproducción de los discursos dominantes, pues éstos estarían contribuyendo a la exclusión social, así como a la fragmentación, en tanto reconoce como formas anómalas otros modos de ser ciudadano que no se incluyen en sus lógicas discursivas. De esta manera se excluye de la ciudadanía "normal” a los no incluidos en los circuitos de mercado, a los consumidores de sustancias psicoactivas, a los discapacitados, a los jóvenes delincuentes y a los sectores de la tercera edad, entre otros. Lo anterior termina afectando los procesos 
identitarios y de reconocimiento social sobre los que estos sujetos ejercen su ciudadanía y sus derechos. Se hace urgente entonces un trabajo para hacer visible lo que hay de estigmatizante en los discursos oficiales y la producción de nuevos discursos que apuesten por la inclusión y la integración social. En este sentido, una concepción política de los discursos de la intervención social se relaciona de manera directa en su compromiso con dos aspectos claves. Por un lado, con el llamado empoderamiento social, es decir, con la posibilidad que tienen los beneficiarios de expandir su libertad de elección y acción, lo que implica incrementar la propia autoridad y control sobre los recursos y las decisiones que afectan su vida. Y por otro, en su vinculación, ya sea como agentes movilizadores o representantes, a las organizaciones de base en procura de un orden social más integrador.

\section{Métodos de intervención social}

Los métodos de intervención social y los modelos de evaluación cristalizan en prácticas y técnicas concretas algunos de los principios descritos anteriormente. Así mismo, constituyen un conjunto de indicios que dan cuenta de las condiciones sociales descritas previamente y de los modos reales en que la intervención ha atendido los retos del contexto. Hoy, la intervención social posee características heterogéneas; se realiza desde múltiples frentes y con distintas metodologías de acción y evaluación. Alguna de la bibliografía estudiada sobre el tema hace referencia a elementos eminentemente técnicos ligados a la construcción de proyectos con sus respectivos instrumentos de ejecución, medición y verificación, a orientaciones teóricas o epistemológicas, al análisis del contexto social que demanda la intervención, al uso de resultados que implica reflexiones sobre los procesos de comunicación y difusión de los hallazgos (sistematización) de la evaluación y finalmente a algunos elementos sobre el rol del interventor. Muy pocos presentan propiamente métodos sistemáticos para adelantar la intervención social.

Las intervenciones sociales y por tanto sus metodologías de acción y evaluación han pasado por distintos procesos de reconceptualización que permiten comprender su estado hoy. Hacia 1960 se enfocaron en integrar profesionales de las ciencias sociales a las problemáticas latinoamericanas, en un contexto de cambio de estas disciplinas que por entonces se adaptaban a las necesidades locales en medio del debate de las teorías del desarrollo. Ya desde ese momento se reflexionaba sobre la escasa participación de la 
academia en procesos de cambio e intervención social. ${ }^{14}$ Específicamente, la sociología hace un intento por superar la sociología científica y desarrollar la denominada sociología de la liberación, que implicaba la coherencia entre las actividades propias de la profesión y los intereses de los pueblos. Nacen así diferentes énfasis en las intervenciones: científico, metodológico, ideológico, vida cotidiana, profesionalización y práctica. ${ }^{15}$ Se expone la necesidad de planificar los problemas sociales y su quehacer se orienta a cumplir con cuatro funciones: el desarrollo de un esquema teórico que orienta la intervención, la determinación de objetivos de acción, la formulación de medios o programas y la evaluación.

En la década de los 80 las intervenciones buscaban la transformación de la realidad por medio de la práctica. Específicamente en el marco de la sociología colombiana son impulsadas las ideas de la IAP. Desde el trabajo social, el concepto de intervención transformadora apela a que los individuos y colectivos modifiquen las condiciones en las que se producen, distribuyen y desarrollan los problemas sociales y propende por la transformación de conocimientos y actitudes de los sujetos. Las acciones y evaluaciones en este contexto estaban concentradas en entender el cambio, alteración, modificación de una situación o proceso respecto a un estado anterior. ${ }^{16}$ Desde la década de los 90 el énfasis de las intervenciones ha estado puesto en apoyar la participación de las comunidades en procesos socioeconómicos y políticos -antes en manos del Estado- que les permitan incluirse en la estructura social, lo que explica el énfasis cada vez más fuerte en intervención comunitaria, empoderamiento y capital social.

Actualmente, a partir de la identificación de problemas, las ciencias sociales utilizan distintos métodos de intervención social que tienen características comunes: 1. Constituyen un conjunto de prácticas que tienen una función integrativa o preventiva; 2. Las prácticas constan de estructuras organizacionales que implican niveles jerárquicos; 3. Se bosqueja una tecnificación, que consiste en la asistencia de un personal mínimamente especializado que además contribuye o guía la acción; y 4. La práctica consta de una localización, es decir, que se produce desde un campo “intrainstitucional” o "extrainstitucional”. ${ }^{17}$ También

\footnotetext{
${ }^{14}$ Lazarsfeld, Paul et al., Planificación sociológica de los problemas sociales. Paidós, Buenos Aires, 1971, (p. 35).

${ }^{15}$ Ezequiel, Ander-Egg. Reconceptualización del servicio social. Humanitas, Buenos Aires, 1971. Pp. 10.

16 Natalio, Kinersman. El Método: Intervención transformadora. Humanitas, Buenos Aires, 1986. Pp. 14

17 Cf. Castel, Robert. Op. Cit. pp. 39 a 43.
} 
se presentan diferencias metodológicas y técnicas visibles en la descripción de cada una de ellas. Se registran a continuación sólo algunas de las más importantes:

\section{A) La Investigación Acción Participativa (IAP)}

La Investigación Acción Participativa involucra estrechamente en el proceso de investigación el saber de las comunidades y su empoderamiento para la transformación de su propia realidad. Parte de la idea de que las comunidades marginadas pueden ser fortalecidas en sus conocimientos como una vía para emprender acciones exitosas en la superación de su exclusión social. La I.A.P. propone las técnicas de 1) Investigación colectiva, 2) Recuperación crítica de la historia, 3) Valoración y aplicación de la cultura popular y 4) Producción y difusión del nuevo conocimiento. La primera se refiere al uso de información recolectada y sistematizada en la comunidad, producto de sus acciones, como fuentes de datos y conocimientos objetivos que resultan de reuniones, comités, asambleas públicas, y demás actividades colectivas. La segunda técnica permite obtener, de primera mano, información sobre la historia de la comunidad y específicamente sobre los elementos del pasado que han mostrado algún grado de efectividad o no en la superación de condiciones de marginalidad. La tercera técnica se basa en el reconocimiento de los valores esenciales de una comunidad determinada. Esto permite que elementos culturales y étnicos, frecuentemente ignorados en la práctica política, como la música, el arte, los deportes y otras expresiones relacionadas con los sentimientos, la imaginación y las tendencias lúdicas y artísticas sean utilizadas. Por último, la aplicación y difusión del nuevo conocimiento es una técnica integral de la investigación en tanto se convierte en un mecanismo de evaluación permanente del proceso, que sirve como experiencia a nuevas investigaciones participativas. En esta técnica se establecen al menos tres niveles de comunicación de acuerdo a quien vaya dirigido el mensaje (personas con baja escolaridad, dirigentes populares o intelectuales). En primera instancia, la información recolectada es sistematizada y devuelta a la comunidad en formatos acordes con su capacidad para entender los mensajes y que pueden ser escritos, orales o visuales. El carácter científico u objetivo de esta metodología descansa en su verificabilidad social, que se apoya en la legitimidad dada por el consenso emanado de la comunidad en torno a la información. Dicha información es recogida en una relación sujeto-sujeto entre los investigadores externos y los miembros de la comunidad dentro de un proceso dinámico y recíproco. 
Desde el plano estrictamente metodológico, más que un modelo cerrado que oriente y guíe la investigación, la IAP propone una serie de criterios que permitan avanzar en los procesos de participación social. Éste implicaría el desarrollo de momentos como: conocimiento, reconocimiento y contactos con la comunidad; identificación de la problemática social de las comunidades; acción, apoyo y colaboración, como proceso de conocimiento y legitimación; justificación de la presencia del investigador para lograr eficacia, consenso y simetría en la relación con las comunidades. Por su parte, el proceso de investigación colectiva propende por una relación dialogante durante todo el proceso de reflexión. La IAP comprende la posibilidad de que se generen tensiones y diferencias entre la elaboración del conocimiento que efectúa el investigador y la ideología de los sujetos intervenidos. Estas tensiones no son concebidas como "negativas" pero demandan de la comunidad presión ideológica y del proceso la creación de ámbitos de discusión donde sujetos intervenidos e investigadores puedan ubicarse en condiciones de igualdad.

\section{B) El capital social}

Para el sociólogo P. Bourdieu, el capital social se constituye en una suerte de red de relaciones sociales que potencian las posiciones de los individuos en el espacio social. Lo define como "la totalidad de los recursos potenciales o actuales asociados a la posesión de una red duradera de relaciones más o menos institucionalizadas de conocimientos y reconocimientos mutuos. Expresado de otra forma, se trata aquí de la totalidad de recursos basados en la pertenencia a un grupo. (...) En la práctica, las relaciones de capital social sólo pueden existir sobre la base de relaciones de intercambio materiales y/o simbólicas”. ${ }^{18}$ Así, para el referido autor, el capital social es una suerte de tejido social que permite a las personas movilizar a su favor apoyos, ayudas, refuerzos y solidaridades que finalmente posibilitan el acceso a diferentes órdenes de recursos. El capital social, junto a otros tipos de capitales, se constituye en condiciones claves que permiten el mejoramiento de las condiciones de vida de los colectivos sociales. Pero lo que de alguna manera potencia el capital social, son fundamentalmente las formas organizadas a las que pertenecen los individuos, a las redes sociales en que logran inscribirse, como las relaciones de parentesco, los clubes sociales o deportivos, el cultivo de las amistades, la participación en reuniones, las relaciones de vecindad, la vida comunitaria, la adscripción activa en organizaciones

\footnotetext{
${ }^{18}$ Bourdieu, Pierre, Poder, derecho y clases sociales, Editorial Desclée de Brouwer. S.A., Bilbao, 2000, (p.
} 148) 
comunitarias y ciudadanas, etc. Todo lo anterior, entre otros, produce conocimientos y reconocimientos que amplían las redes de relaciones sociales, que como capital social potencia las posibilidades del individuo en términos de sus otros capitales: político, cultural, económico, etc.

Visto el capital social de manera más “procedimental”, como mecanismo de medición y desarrollo social, tendríamos que referirnos, por ejemplo, a R. Putnam. Este ha definido el capital social como el patrimonio acumulado en el tiempo que le permite a una sociedad actuar organizadamente sobre la base de valores como la confianza, la cooperación, la solidaridad, la reciprocidad y las redes de compromiso, en procura de un bienestar colectivo. ${ }^{19}$ Así, es una de las posibilidades prácticas de organización para el progreso social colectivo. El capital social es concebido como un bien público poco valorado por algunos agentes públicos y privados. Por tratarse de un bien, tiene la capacidad de ser acumulable y facilitar, según su cantidad, la capacidad de resolver situaciones y afectar instituciones grandes y complejas. Se compone de tres elementos básicos: la confianza, las normas y las redes. La confianza, como mecanismo, se apoya en una reciprocidad social generalizada y mutua en la que median recomendaciones y valoraciones de los miembros del grupo. Esta característica permite que la confianza personal se transforme en confianza social lubricando las posibilidades de cooperación colectiva y dándole un valor en la práctica. En segundo lugar, las normas sociales regulan la acción de los otros. Se mantienen a lo largo del tiempo a través de la socialización y las sanciones y se desarrollan de manera exitosa debido a su capacidad de facilitar las transacciones y la cooperación al interior de un grupo. Las normas son de dos órdenes: recíproco generalizado y recíproco equilibrado. Las primeras, se caracterizan por ser flexibles, cotidianas y enmarcarse en un proceso cuya remuneración y beneficios se dan en el largo plazo. Las segundas, mucho más restringidas, se basan en el intercambio simultáneo y no necesariamente trascienden. En tercer término, las redes se caracterizan por ser un elemento característico de comunidades de diferentes épocas y sirven de canal natural para la circulación de la confianza. Pueden distinguirse dos formas particulares de redes: las verticales y las horizontales. Las primeras, se fundamentan en conceptos como el poder y las jerarquías; en ellas es proclive la dependencia y explotación. Las segundas, por el contrario, se basan en relaciones flexibles,

\footnotetext{
${ }^{19}$ Putnam, Robert. Para hacer que la democracia funcione, Editorial Galac, Caracas, 1994. Los postulados de Putnam pueden enmarcarse en un ejercicio analítico más amplio orientado por Coleman. Ver: Coleman James S., Foundations of Social Theory, Harvard University Press, Cambridge, 1990.
} 
amistosas y que facilitan la circulación de la confianza y de elementos críticos que permiten construir, expandir y regenerar el tejido social. Las dos coexisten y contribuyen a mantener unida a la sociedad.

Un enfoque liderado por el Banco Mundial permite reconocer lineamientos metodológicos que indican la necesidad de concentrarse en conocer los activos de la comunidad y los servicios de los que dispone en dos sentidos: capital social estructural y capital social cognitivo. El primero hace referencia a las instituciones formales e informales con las cuales la comunidad interactúa y que determinan factores de desarrollo social, sus formas de liderazgo, importancia, acceso, impacto, niveles de eficacia y demás. El segundo, se empeña en conocer los niveles de participación, la cultura organizativa, la historia de los grupos y demás elementos que dan cuenta de la apropiación por parte de la comunidad, de las riendas de su desarrollo. ${ }^{20}$

\section{C) Participación social y comunitaria}

Este método, en general consiste en la intervención desde sectores de la sociedad en numerosos ámbitos y problemas sociales. ${ }^{21}$ Estima de manera importante la participación de la comunidad, por tanto se distancia del Estado de Bienestar, pues valora positivamente la retroalimentación y reformulación de los procesos como dinámica bidireccional. Emplea como recurso básico el apoyo de la misma comunidad afectada o implicada en las problemáticas sociales. Así, los individuos y las comunidades deben estar involucrados en las decisiones y programas que afectan sus vidas para resignificar sus problemas y generar alternativas para solucionarlos de manera autónoma. ${ }^{22}$ Este tipo de proceso de intervención

\footnotetext{
${ }^{20}$ La metodología de investigación sobre capital social es sólida. Hay indicadores e instrumentos diseñados tanto para estudios cualitativos como cuantitativos que trabajan con más de 60 variables relativas a: características de la comunidad, demografía, capital social estructural. Este último se refiere al potencial históricamente acumulado por las acciones y experiencias de una comunidad determinada que les permite agruparse, interactuar con instancias formales e informales del sistema social, adelantar procesos de desarrollo y transformación estructural para el acceso a mejores condiciones de vida, e incluye: densidad organizativa y sus características, redes y organizaciones de apoyo mutuo, exclusión, acción colectiva, acción colectiva y participación sectorial específica, resolución de conflictos. A su vez, el capital social cognitivo hace referencia a las formas de relación entre los miembros de una comunidad determinada, de donde surge una red de interacciones mediadas por normas de reciprocidad y solidaridad que contribuyen al bienestar individual o colectivo), e incluye: solidaridad, confianza, reciprocidad y cooperación.

${ }^{21}$ Es un proceso que pretende intervenir problemáticas sociales asociadas a la pobreza, subdesarrollo, exclusión social, falencias sociales, precariedad de condiciones, la familia, la tercera edad, la enfermedad mental, las adicciones, las discapacidades y las enfermedades crónicas, etc.

${ }^{22}$ Para una mayor información sobre este método de intervención, ver: Gracia, Enrique, El apoyo social en la intervención comunitaria, Paidós, Barcelona, 1997.
} 
puede ser asumido al menos por tres actores: el Estado, la comunidad y la sociedad civil, generalmente representada por profesionales de sectores académicos. ${ }^{23}$

Cuando es el Estado quien la asume, se elaboran planes, programas, proyectos y acciones, encaminadas a atender problemas sociales. Las ventajas son evidentes pues el Estado cuenta con los recursos técnicos, profesionales, financieros y humanos, que puestos al servicio de la intervención, potencian las posibilidades de la comunidad.

Cuando la intervención es asumida por la sociedad civil representada en profesionales del sector académico, la responsabilidad se concentra en la gestión y ejecución de proyectos que se organizan en torno a problemáticas y objetos de intervención específicos. Se financian a través de la presentación de proyectos a distintas instancias locales, nacionales e internacionales.

Cuando la iniciativa es asumida por la comunidad, implica la presencia de formas organizativas de base capaces de liderar y gestionar procesos sociales. Uno de los ejes básicos en el proceso de intervención comunitaria es la participación, concepto íntimamente relacionado con la democracia y que conlleva el uso de ciertos mecanismos previstos por la ley como la consulta, el referendo, la veeduría, el cabildo abierto y la iniciativa legislativa, entre otros.

Metodológicamente, la intervención comunitaria se concentra en dos procesos: la aproximación a las comunidades y las formas de organización del trabajo. La primera implica un ejercicio de diagnóstico participativo y la formulación posterior de un proyecto con base en los problemas priorizados. La aproximación suele apoyarse en ejercicios del orden de la cartografía social, la elaboración colectiva de árbol de problemas y sondeos participativos, todas ellas técnicas que, desde el proceso de diagnóstico, garantizan la participación de los actores y se convierten en insumos claves para el ejercicio de sistematización. La segunda implica la participación de líderes, cuadros gestores y la comunidad en general en la convocatoria del equipo de trabajo y la distribución eficiente de la información. El equipo coordinador se caracteriza por la rotación de los cargos, la presencia de una estructura estable que lidera y gestiona procesos y busca la democratización de la información a través de asambleas, conferencias, seminarios, grupos focales, talleres, mesas redondas, lluvias de ideas, sociodramas y demás actividades que permitan lograr acuerdos, consensos y decisiones conjuntas alrededor de una acción.

\footnotetext{
${ }^{23}$ Cf. Marchioni, Marco, Comunidad, participación y desarrollo. Teoría y metodología de la intervención comunitaria, Editorial Popular, Madrid, 1999.
} 


\section{D) La intervención sociológica}

El método de intervención sociológica propuesto por Alain Touraine ${ }^{24}$ es ante todo un procedimiento de análisis que permite a los actores implicados en una acción colectiva acceder a formas de conciencia política sobre su acción y el sentido último de la misma. Les permite, en colaboración con investigadores más o menos ajenos a su organización, hallar la conexión de sentido entre la acción colectiva y el movimiento social que recubre, el vínculo entre la lucha social y el movimiento que cuestiona el orden de la dominación social y político general. Este método se centra en las conductas colectivas resultado de conflictos sociales, que en última instancia cuestionan los modos de dominación social. El método plantea en principio establecer un vínculo permanente y estrecho entre los actores claves de la acción colectiva y la acción misma (huelga, paro, etc.). A su vez, este grupo debe considerarse como representante de un movimiento mucho más amplio que la acción emprendida. Ellos como actores claves de la acción colectiva emprendida deben elaborar el sentido de las prácticas de la acción, lo cual no se logra de manera individual, ni con su propio colectivo de compañeros de lucha. Se requiere, señala Touraine, de encuentros entre los actores implicados en el conflicto (en una huelga por ejemplo, el encuentro entre patronos y obreros), para que en sus intercambios e interacciones se pueda desideologizar el carácter de la lucha. A estas alturas del proceso, señala el autor, el grupo puede adelantar una suerte de socioanálisis del grupo capaz de demandar investigadores que, elaborando una hipótesis del vínculo entre la acción colectiva y el movimiento social (en el caso de los obreros, el enlace posible puede ser entre la huelga como acción colectiva y la lucha de clases, por ejemplo), lo puedan adoptar y elevar así el nivel de la lucha emprendida. Al final, lo que se produce es una especie de relato analítico de la lucha, una suerte de hipótesis que reinterpreta la historia del grupo y que puede servir para analizar y asumir nuevas iniciativas en otras acciones futuras. Se constituye así una sociología permanente que implica acción colectiva, análisis de la misma, autoanálisis e hipótesis y nuevas acciones colectivas. Este método fue puesto en práctica por A. Touraine en acciones colectivas con grupos de estudiantes, ambientalistas, de mujeres, etc. ${ }^{25}$

\footnotetext{
${ }^{24}$ Touraine, Alain, “Introducción al método de la intervención sociológica”, en: Estudios sociológicos, Vol. 4, No. 11, México, Colmes, mayo-agosto 1986.

${ }^{25}$ Ver: Touraine, Alain, Movimientos sociales hoy. Actores y analistas. Editorial Hacer, Barcelona, 1990.
} 


\section{Sobre los modelos de evaluación de proyectos de intervención social}

Los enfoques evaluativos han estado fuertemente determinados por lógicas de medición positiva, ligadas a la aplicación rigurosa de métodos validados por la ciencia social, no necesariamente afines o congruentes con las dinámicas de una intervención participativa. Estos métodos son exigidos y hasta diseñados por los agentes financiadores, quienes requieren permanentemente la medición objetiva del rendimiento de las inversiones económicas. ${ }^{26}$ Esto plantea un reto a las evaluaciones de la intervención: dar cuenta de dichas inversiones, pero superarlas en su dimensión objetiva para encontrar aquellos cambios sutiles, tanto de orden individual como colectivo que pueden estar señalando transformaciones vitales para la superación de problemas sociales. Desde esta perspectiva, si bien los métodos de las ciencias sociales son útiles, deben ampliarse e incluir herramientas provenientes de distintas disciplinas que puedan enriquecer la manera como se posa la mirada sobre las intervenciones y el cálculo de rendimientos que las cifras e indicadores ortodoxos no suelen mostrar.

En la actualidad, un elemento transversal a los procesos evaluativos es la rendición de cuentas. Bien sea que las intervenciones sean financiadas por agentes oficiales o privados, entran en consideración al menos cuatro elementos evaluativos: la eficacia, la efectividad, la sostenibilidad y el desempeño institucional. Lo que hallamos en general, son formas de evaluar a partir de indicadores en el marco de una lógica económica empresarial. Todos ellos relacionan estrechamente dos momentos de la intervención: la planificación y la evaluación. La planificación, en esencia, consiste en establecer qué se hará y los recursos que se emplearán para ello. La evaluación no es otra cosa que la estricta supervisión de las acciones adelantadas y del valor social que generan. En cualquier caso, la evaluación se refiere a las acciones planeadas y a las realizadas; esto es lo que permite comparar los planes con las acciones que los materializaron y sus consecuencias. Toda evaluación de la planificación requiere: identificar la disponibilidad de recursos, definir la finalidad de los recursos en función de una apuesta política y diseñar mecanismos de acción y evaluación que garanticen la relación adecuada entre lo proyectado y lo ejecutado. Esto involucra al menos dos dimensiones: la social y la institucional, lo cual significa que al evaluar hay que

\footnotetext{
${ }^{26} \mathrm{Al}$ respecto es importante ver los instrumentos de orden cuantitativo y cualitativo diseñados y promovidos por el Banco Mundial para la medición de capital social, o el Marco Lógico exigido por el BID para presentación y evaluación de las propuestas que financian, todo inscrito en una lógica de mercado.
} 
hacerlo hacia fuera (ver el rédito social que produce la intervención) y hacia adentro (ver la manera en que se ejecutan los recursos y cómo se planifican). El terreno de la evaluación es flexible, involucra múltiples variables y dimensiones y requiere ser tratado con sumo cuidado para determinar no solo las variables que se trabajan dentro de cada intervención sino la situación en que cada variable se encontraba antes de la misma, así como su variación por causas inherentes o externas al proceso interventor. De igual manera, implica dirigir la mirada sobre las consecuencias sociales del proyecto evaluado. Esto necesariamente requiere reflexionar sobre diferentes tópicos: la efectividad y sostenibilidad, la eficacia y eficiencia en el desempeño institucional, la importancia de los indicadores, la tensión entre las relaciones de poder y la transparencia, el equilibrio entre productos, resultados y beneficiarios y, las organizaciones y usuarios y su relación con los efectos.

El primer tópico, la efectividad y sostenibilidad, implica pensar que las intervenciones están orientadas a producir valor público, es decir, rendimientos sociales, económicos y políticos que contribuyen a satisfacer necesidades humanas en sociedades determinadas, por tanto, se requiere planificar, controlar y rendir cuentas en función del valor público. Se espera que los recursos invertidos arrojen consecuencias positivas, es decir que transformen una situación inicial negativa que está registrada. Las transformaciones son resultado de acciones concretas, coherentes y sostenidas que generan cadenas de valor ligadas a las maneras en que se asignan los recursos y las consecuencias que ellos originan. La cadena de valor termina con la asignación de recursos que está determinada por la planificación, ésta a su vez es el reflejo de una necesidad políticamente establecida como prioritaria.

Se evalúa como efectividad el logro de resultados como consecuencia final de la asignación de los recursos y como sostenibilidad el mantenimiento de los mismos una vez finalizada dicha asignación. ${ }^{27}$ Las consecuencias de las acciones provenientes de las asignaciones de recursos pueden ser permanentes o transitorias; así, la relación entre efectividad y sostenibilidad no es necesariamente constante. Pueden producirse efectos eficaces pero no sostenibles, efectos moderados pero sostenibles o fracasos en la asignación de recursos. En cualquier caso, esto pone en evidencia tanto la dificultad para medir los efectos como para programarlos y para relacionarlos entre sí como factores de éxito o fracaso de la intervención. Hay una tensión intrínseca a la medición de una efectividad

\footnotetext{
${ }^{27}$ Hintze, Jorge. Instrumentos de evaluación de la gestión del valor público. Tecnología para Organización Pública. TOP, Universidad Nacional del Litoral, Argentina, 2003, (p. 3).
} 
sostenible, producto de las distintas dimensiones que están involucradas en la intervención y la variabilidad de las mismas.

El segundo tópico, la eficacia y eficiencia en el desempeño institucional, implica el cumplimiento de los planes o términos de referencia de los contratos para inversión social. Indica la necesidad de mirar la eficacia, eficiencia y viabilidad en el plano operativo de determinadas acciones institucionales, la correspondiente planificación de la intervención que se haya realizado y el análisis sobre el compromiso con los niveles políticos, ideológicos y éticos involucrados. En este caso, la eficiencia alude a la medida en que se aprovechan los recursos, es decir, cuál es la relación entre el valor logrado y los recursos empleados. La eficiencia es un criterio de evaluación que se refiere a los procesos (dónde y cómo se usan los recursos), mientras que la eficacia se refiere a los resultados de los mismos. Además, debe considerarse la viabilidad, que se define como qué tanto es posible orientar los procesos hacia mayores niveles de eficiencia y eficacia sin entrar en contradicción con las políticas e intereses ideológicos. Las gestiones con mayor éxito son aquellas que logran, simultáneamente, altos niveles de eficacia y eficiencia. pero en la práctica existe una gama de posibilidades que oscilan entre la máxima eficiencia y eficacia y la total carencia de ellas.

Un tercer tópico: las Tensiones entre las relaciones de poder y la transparencia, permite encontrar sistemas de evaluación que estén insertos, de manera permanente y sistemática, en el orden institucional y que contribuyen a hacerlo más transparente. La transparencia implica la presencia de dos aspectos: la amplitud de la información de la que se dispone para evaluar y la validez de la misma. Estos dos elementos a su vez dependen de las relaciones de poder entre los actores involucrados en el proceso de intervención. Cada grupo de actores es heterogéneo y representa distintos intereses. Los actores son afectados de una u otra manera por la transparencia resultante de esas informaciones legitimadas y disponibles. La finalidad última de las rendiciones de cuentas y evaluaciones sobre lo logrado con el uso de los recursos públicos es que la ciudadanía disponga de información regular y confiable sobre el comportamiento de las principales variables de la gestión pública. Se busca que, en el plano político y estratégico, tengan acceso a información sobre los efectos del accionar público sobre la sociedad y, que en el plano operativo, tengan claro el funcionamiento del aparato del Estado y su gestión. 
De acuerdo con algunos autores, ${ }^{28}$ existen seis condiciones que favorecen la gestión transparente: 1) La presencia de sistemas de información que satisfagan las necesidades de los actores involucrados en la intervención. 2) La existencia de procesos que posibiliten la permanente rendición de cuentas con soportes normativos. 3) La responsabilización de conductas y en general unos marcos contractuales con base jurídica. 4) La presencia de un plan de acción organizativo y presupuestal ligado a metas concretas. 5) Autoridades encargadas de la ejecución. 6) Uso de indicadores legítimos construidos como valores significativos para los actores interesados. De ahí la importancia del cuarto tópico: atender los indicadores que se refieren a la relación entre algún fenómeno que resulta observable directamente y otro que no. ${ }^{29}$ La calidad de dicha relación es lo que determina la confiabilidad y validez. Se entiende por confiabilidad la medida en que el indicador puede ser interpretado de la misma manera en diferentes oportunidades y por validez la probabilidad de que la coherencia entre el fenómeno observable y el que interesa medir sea alta. Calidad del indicador es la presencia simultánea de ambas características. En general se trabaja con tres tipos de indicadores: de productos, de resultados y de efectos. Estas definiciones son relativas a los ámbitos de evaluación a los que se apliquen los indicadores. Indicadores de producto son los referidos a aspectos específicos y concretos a los que se han asignado recursos (son indicadores de gestión). Los indicadores de resultado están ligados a los logros obtenidos con la inversión del recurso y los indicadores de efectos se refieren a transformaciones de la situación social (los dos últimos son indicadores de logros políticos y estratégicos).

Para el quinto tópico es necesario preguntarse: ¿Qué deja un proyecto de intervención a una comunidad? Las consecuencias de las intervenciones no siempre son objetivas y su evaluación depende de qué tanto se hayan planeado los productos, entendidos como los resultados concretos que las instituciones entregan a los usuarios y que son el resultado de la inversión de un determinado recurso. Con frecuencia se confunden los productos con los resultados, por eso es importante señalar que los resultados son las consecuencias que se

\footnotetext{
${ }^{28} \mathrm{Al}$ respecto ver: Quintero, Víctor Manuel, Los proyectos sociales, Fundación FES, Cali, 1991. Ver también Hintze, Jorge, Op. Cit.

${ }^{29}$ En general las intervenciones involucran acciones que no son directamente observables sino que deben traducirse a elementos observables empíricamente. Por ejemplo, en la variable "mejoramiento de la cobertura de sistemas de salud", el número de nuevos inscritos al sistema en un periodo de tiempo determinado se constituye en el indicador empírico verificable, de otra manera el "mejoramiento" en sí mismo se constituye en un intangible.
} 
esperan al desarrollar o lograr los productos. Los productos son la vía para el logro de los resultados y, por lo tanto, se concretan en procesos, y acciones específicas. Debe existir equilibrio entre productos, resultados o efectos y beneficiarios. Todo proceso de intervención pretende generar productos que benefician a terceros llamados destinatarios. Hay distintos tipos de ellos; los más inmediatos son los usuarios, es decir, quienes reciben las acciones de la intervención de manera directa. Otro tipo de destinatarios son los beneficiarios que son quienes satisfacen necesidades a través de los usuarios. Estas distinciones permiten reconocer que las intervenciones generan cadenas de satisfacción que son determinantes al momento de evaluar, pues indican dos niveles distintos de impacto según se reciban beneficios directos o indirectos.

Los efectos son, en realidad, resultados más lejanos o indirectos y, por lo tanto, más inciertos en cuanto a su logro. Sin embargo, son lo que más importa en toda organización, porque se refieren a su razón de ser. Los efectos son aquellos estados a los que frecuentemente se alude como “finalidades”, “objetivos” y otras denominaciones, más o menos imprecisas, pero que deben indicar cuándo se va en sentido contrario y cuándo no. Las políticas, tanto en las organizaciones públicas como en las privadas, se refieren esencialmente a los efectos. ${ }^{30}$ Los efectos son consecuencias de las acciones institucionales que ejecutan el proyecto. Algunas de estas consecuencias son más inmediatas (también llamadas efectos de primer nivel) y otras más mediatas (o de segundo nivel). Todo análisis evaluativo debe permitir el desarrollo de una cadena causal que une los productos y los usuarios con los efectos, es decir el qué con el para qué y con el para quién.

\section{Pistas generales para pensar críticamente la intervención social}

Así, frente a la nueva cuestión social y el distanciamiento que de la misma toma el Estado, podemos señalar tres perspectivas posibles que, como apuesta política desde una dimensión académica, ${ }^{31}$ plantean luces sobre los procesos de intervención social actuales. Una mirada que invita a pensar críticamente la intervención social hoy.

\footnotetext{
${ }^{30}$ Hintze, Jorge. Matriz de producción externa. Tecnología para Organización Pública. TOP, Universidad Nacional del Litoral, Argentina, 2003, (p. 18).

${ }^{31}$ Estas pistas han sido elaboradas a partir de los textos de Robet Castel, Las metamorfosis de la cuestión social: crónica del salariado; Richard Sennett, El Respeto; y Alfredo Carballeda, La intervención en lo social: exclusión e integración en los nuevos escenarios sociales.
} 
En primer lugar, una idea sugerida por Robert Castel: rehacer el Contrato Social. Frente a los grandes contingentes de individuos ubicados en condición de desconversión, vulnerabilidad y desafiliación social que los coloca por fuera de la estructura social, en las márgenes de las redes de sociabilidad y sin un sistema de protección social que los respalde, se producen procesos de desintegración social y anomia. ${ }^{32}$ Ante semejante situación, se hace necesario movilizar la creación de espacios de trabajo, formas de solidaridad y desarrollo de ciudadanía que promuevan procesos de inclusión de todos como forma de hacer sociedad.

En segundo lugar, producir formas de intervención social en condiciones de respeto, planteamiento central en Richard Sennett. Frente al problema de la desigualdad social hay que señalar que ésta tiene implicaciones en la distribución del respeto en las relaciones sociales. La falta de respeto no concede reconocimiento e importancia social a los individuos de manera equitativa. La escasez de respeto hacia las masas es una forma de desigualdad y de exclusión de grupos sociales y constituye una realidad social. En este sentido se hace necesaria la generación de formas de asistencia social que consideren la autonomía de los individuos y propendan por la construcción de redes de conexiones que posibiliten la relación respetuosa entre sujetos.

En tercer lugar, generar procesos de intervención microsociales, consideración señalada por Alfredo Carballeda. Como se ha mencionado previamente, las crisis políticas, sociales y económicas generan una problemática de desintegración y fragmentación social que conllevan a la ruptura de las solidaridades y fractura del tejido social. En consecuencia, la alternativa es la intervención comunitaria desde los espacios microsociales, capaces de promover formas de solidaridad y recuperación crítica y reflexiva de la historia, así como el uso de técnicas de intervención que desde la lúdica funden nuevas e imaginativas formas de relación social. Todo lo anterior debe posibilitar organización e integración que apunte a configurar escenarios incluyentes de ciudadanía.

En definitiva, y con base en los autores referidos, se sugieren tres vías para pensar la intervención social hoy. De un lado, el Estado se halla en el centro de la salida frente a la nueva cuestión social, es él con su gran capacidad institucional quien debe jugar de nuevo un papel central frente a los procesos de desafiliación actuales. Por otra parte, se indican

${ }^{32}$ Cf. Castel, Robert. Op Cit. 
salidas de carácter simbólico y relacional capaces de impactar positivamente las formas de interacción, por vía de una distribución más equitativa del respeto. Y, por último, se plantean alternativas más de carácter comunitario en contextos microsociales, como modo de conjurar los problemas de desintegración social. Por supuesto que son alternativas para nada excluyentes y que pueden aportar a procesos de intervención social más incluyentes y con contenidos democráticos. 